\title{
VARIAÇÃO DE VAZÃO DE GOTEJADORES DE FLUXO NORMAL ENTERRADOS NA IRRIGAÇÃO DE CAFÉ ${ }^{1}$
}

\author{
LUIS F. FARIA ${ }^{2}$, RUBENS D. COELHO ${ }^{3}$, RONALDO S. RESENDE ${ }^{4}$
}

RESUMO: Este trabalho teve como objetivo obter informações sobre o desempenho de gotejadores enterrados (irrigação subsuperficial), quanto ao aspecto de variação de vazão em função da intrusão radicular da cultura do café. As mudas de café foram irrigadas por sete modelos diferentes de gotejadores de fluxo normal, instalados a duas profundidades (15 e $30 \mathrm{~cm}$ da superfície do solo) e em dois níveis de depleção de água no solo (tratamentos úmido e seco). O trabalho foi conduzido em vasos e sob ambiente controlado, utilizando mudas de cafeeiro em estágio inicial de desenvolvimento. Concluiu-se que, até os 120 dias do início do experimento, não houve modelo de emissor que se destacasse quanto à penetração de raízes e, a partir daí, diferenças na suscetibilidade dos modelos foram observadas, podendo-se agrupar os modelos avaliados em função do grau de redução de vazão. Os níveis de irrigação não apresentaram resultados conclusivos até 120 dias do início do experimento, porém, considerando todo o período do experimento, observaram-se evidências de que o sistema radicular é mais agressivo na camada mais profunda de solo $(30 \mathrm{~cm})$ e para o tratamento úmido.

PALAVRAS-CHAVE: gotejamento, intrusão radicular, entupimento.

\section{FLOW VARIATION OF REGULAR FLOW EMITTERS IN SUBSURFACE DRIP IRRIGATION IN COFFEE CROP}

SUMMARY: This work aimed to quantify drippers performance under subsurface drip irrigation (SDI), regarding the flow variation due to root intrusion under coffee crop. Coffee seedlings were irrigated by seven different models of commercial drippers, in two depths (15 and $30 \mathrm{~cm})$ and in two soil water depletion levels (Wet and Dry treatments). It was concluded that until 120 days from the beginning of the experiment there was not a dripper that highlighted regarding the relationship of the penetration of roots, and starting from there, differences in the susceptibility of the models were observed, and the models evaluated in function degree of flow reduction could be assemble. The irrigation levels didn't present conclusive results until 120 days from the beginning of the experiment, even so, considering the whole period of the experiment evidences were observed that the root system is more aggressive in the deepest layer of soil $(30 \mathrm{~cm})$ and for the wet treatment.

KEYWORDS: drip irrigation, root intrusion, plugging.

\footnotetext{
${ }^{1}$ Extraído da dissertação de Mestrado do primeiro autor apresentada à ESALQ-USP. Projeto financiado pela FAPESP.

${ }^{2}$ Eng ${ }^{\circ}$ Agrícola, M.Sc. em Agronomia - Irrigação e Drenagem, Av. Pádua Dias, 11, Piracicaba - SP, e-mail: 1ffaria@ yahoo.com.br.

${ }^{3}$ Eng ${ }^{0}$ Agrônomo, Prof. Dr., Departamento de Engenharia Rural, ESALQ/USP, Piracicaba - SP.

${ }^{4}$ Eng $^{\mathrm{o}}$ Agrônomo, Doutor, Pesquisador da Embrapa Tabuleiros Costeiros, Aracaju - SE.

Recebido pelo Conselho Editorial em: 9-5-2002

Aprovado pelo Conselho Editorial em: 12-7-2004
} 


\section{INTRODUÇÃO}

A uniformidade de emissão de água pelos gotejadores é fator fundamental ao sucesso do empreendimento. Para a realização de um eficiente manejo de água e fertirrigação, é necessário que a uniformidade de aplicação de água pelos emissores seja a maior possível, pois, com a prática sucessiva da fertirrigação, algumas plantas podem estar recebendo quantidade menor de fertilizantes que outras e respondendo diferentemente em produção.

Os sistemas de irrigação localizados apresentam como principal vantagem a eficiência de uso e de aplicação da água. AYARS et al. (1999) citam também como vantagem dos sistemas de gotejamento enterrados o melhor aproveitamento da água de irrigação e dos nutrientes aplicados nesta, o que deverá resultar em melhor qualidade dos produtos agrícolas. ZOLDOSKE et al. (1998) afirmam que os sistemas de gotejamento enterrados, tanto para culturas de ciclo curto quanto para as culturas perenes, poderão ter vida útil igual ou superior a 20 anos.

Para SUAREZ-REY et al. (1999), o fato de, na irrigação enterrada, se aplicar água diretamente na zona radicular, possibilita a utilização de águas residuais, pois reduz o risco de transmissão de doenças, além de minimizar as perdas de água por evaporação.

Os fatores que afetam a uniformidade de aplicação de água, seguem a seguinte ordem: obstruções, coeficiente de variação de fabricação, expoente de descarga do emissor, sensibilidade do emissor à temperatura e variações de pressão, entre outros (SOLOMON, 1985).

O entupimento dos emissores na malha hidráulica é um grande desafio para a operação e a manutenção de um sistema de irrigação por gotejamento, levando muitos irrigantes ao insucesso com essa tecnologia (GHAEMI \& CHIENG, 1999). As principais fontes causadoras de entupimento em sistemas localizados, identificados por GILBERT \& FORD (1986), são de natureza química, relacionadas à precipitação de elementos como cálcio e ferro, de natureza física, sendo partículas do solo e pequenos animais (formigas, aranhas, ovos de lesmas, etc.) as principais causas, e de natureza biológica, relacionado a algas e mucilagem bacteriana, principalmente.

A intrusão de raízes no gotejador constitui-se em fonte adicional de entupimento, caracterizada como de natureza física, diretamente relacionada a sistemas de gotejamento enterrado. Fatores como variedade plantada, manejo da irrigação, características do solo, além de características construtivas do emissor utilizado, podem determinar o potencial de ocorrer o intrusionamento, bem como seu nível de dano na hidráulica do sistema de irrigação.

RUSKIN \& FERGUSON (2000) relatam quatro maneiras de evitar a intrusão radicular: (1) emissores com barreiras mecânicas; (2) adição do herbicida trifluralina na água de irrigação; (3) incorporação da trifluralina no plástico do emissor, e (4) incorporação de trifluralina no filtro de discos.

A frequiência de irrigação é fator fundamental à prevenção contra a intrusão radicular. O sistema radicular não invade emissores em solos saturados ou próximos à saturação; portanto, não havendo depleção elevada de água no solo, não ocorrerá intrusão radicular (MEAD, 2002).

A utilização de produtos já consagrados contra a intrusão radicular, como emissores impregnados com trifluralina, nem sempre é economicamente viável, pois esses produtos têm custo de aquisição em torno de $100 \%$ mais elevados que produtos convencionais comercializados no Brasil. Tendo em vista o caráter danoso e irreversível da intrusão radicular em gotejamento enterrado, este trabalho teve o objetivo de verificar as seguintes hipóteses: (1) existem diferenças entre emissores no aspecto construtivo quanto à suscetibilidade à penetração de raízes (barreiras físicas); (2) a profundidade de instalação dos emissores pode ter efeito no grau de intrusão radicular, e (3) não havendo déficit no solo, não haverá intrusão radicular nos emissores. 


\section{MATERIAL E MÉTODOS}

\section{Localização do experimento, preparo dos vasos e espécies vegetais utilizadas}

O presente ensaio foi realizado em Piracicaba - SP, no Departamento de Engenharia Rural, Setor de Irrigação e Drenagem da Escola Superior de Agricultura "Luiz de Queiroz" - ESALQ/USP, em condição de ambiente protegido (estufa com cobertura plástica) entre os meses de abril e dezembro de 2001. A estufa utilizada apresentava dimensões de $17,4 \mathrm{~m}$ x 6,4 m, com pé-direito de $3,5 \mathrm{~m}$. A ventilação no interior da estufa era efetuada por meio de manejo de cortinas laterais. Na Figura 1, apresenta-se o arranjo espacial do experimento no interior da estufa.

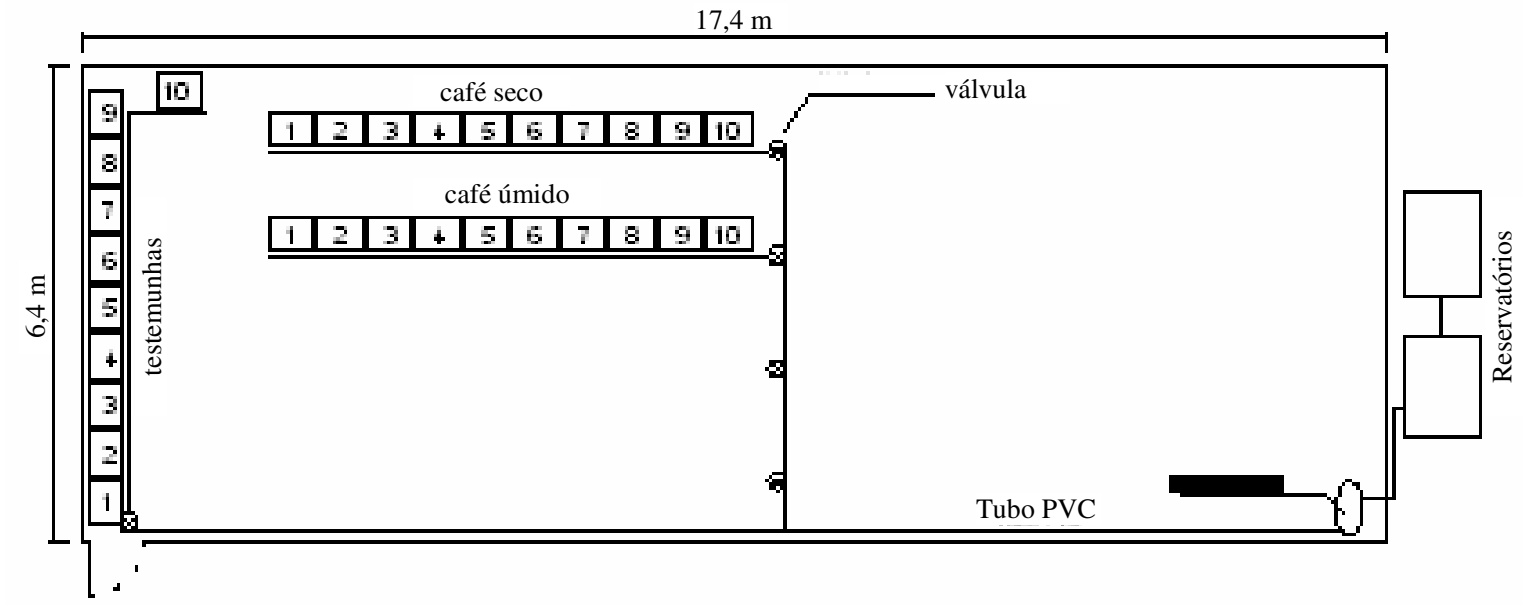

FIGURA 1. Disposição das caixas com plantas de café e com gotejadores enterrados (café seco e café úmido), ao lado das caixas-testemunha sem plantas, utilizadas no experimento conduzido em estufa.

A espécie vegetal utilizada foi o cafeeiro da variedade Icatu. As mudas, em estágio inicial de desenvolvimento, foram transplantadas para vasos de cimento amianto $(0,58 \times 0,43 \times 0,43 \mathrm{~m}) \mathrm{com}$ $100 \mathrm{~L}$ de capacidade. Foram transplantadas nove mudas de café para cada vaso.

\section{Emissores utilizados}

Escolheram-se sete modelos de gotejadores de fluxo normal, dando prioridade aos recomendados pelos fabricantes em sistemas enterrados e também aos mais comercializados no Brasil. Na Tabela 1, são apresentados os emissores selecionados e as principais características de cada um deles.

TABELA 1. Principais características dos tubos gotejadores utilizados.

\begin{tabular}{ccccc}
\hline Fabricantes & Modelos & Vazão $\left(\mathrm{L} \mathrm{h}^{-1}\right)$ & $\mathrm{H}(\mathrm{kPa})$ & Emissor \\
\hline Carborundum & Carbodrip & 2,20 & 100 & Cilíndrico \\
Drip In & Drip In Classic & 1,52 & 100 & Cilíndrico \\
Netafim & Tiram 2000 & 2,05 & 100 & Plano \\
Netafim & Typhoon & 2,00 & 100 & Plano \\
Plastro & Hydro Drip II & 2,30 & 100 & Plano \\
Plastro & Hydrogol & 2,00 & 100 & Cilíndrico \\
Toro Ag. & Aqua Traxx & 1,14 & 70 & Fita \\
\hline
\end{tabular}

Fonte: Catálogos dos fabricantes.

Como os emissores ensaiados são produtos comerciais, os dados e análises aqui apresentados foram codificados para evitar qualquer tipo de especulação comercial dos resultados apresentados. As 
letras utilizadas na codificação dos modelos de emissores (A, B, C, D, E, F, G) não têm nenhuma relação com os nomes comerciais dos produtos nem com a sequiência de emissores apresentada na Tabela 1.

\section{Tratamentos}

Os tratamentos avaliados consistiram de sete modelos de gotejador (A, B, C, D, E, F e G), duas profundidades de instalação desses gotejadores (15 e $30 \mathrm{~cm}$ a partir do nível do solo) e três níveis de irrigação (úmido, seco e testemunha).

Foram montados 20 vasos, e cada um recebeu sete modelos de emissor em cada profundidade de instalação $(15$ e $30 \mathrm{~cm})$, totalizando 14 emissores por vaso. $\mathrm{O}$ tratamento nível de irrigação foi aplicado para 10 dos 20 vasos. Cada tratamento possuía 10 repetições (10 vasos), sendo, portanto, 10 vasos com a cultura do café com o tratamento seco (CFS15 e CFS30) e 10 vasos com o tratamento úmido (CFU15 e CFU30). O manejo da irrigação foi realizado com o auxílio de uma bateria de tensiômetros para cada tratamento (cultura x nível de irrigação).

As leituras tensiométricas foram realizadas sempre no início da manhã. No tratamento úmido, para as duas culturas, determinou-se como limite de tensão de água no solo o valor de -30 kPa para o tensiômetro superficial a 7,5 cm de profundidade para dar início à irrigação. Já no tratamento seco, esperou-se que as plantas apresentassem sintomas de estresse hídrico pela manhã (murcha das folhas) para iniciar a irrigação. Nesse tratamento, procurou-se não promover a saturação do solo nem tampouco elevar a umidade do solo à capacidade de campo, promovendo continuamente déficit hídrico moderado de água no solo, de modo que a planta não viesse a morrer. Foram montados 10 vasos sem cultivo como testemunha (TT15 e TT30); assim, o total de vasos utilizados no experimento foi 30 , sendo 20 com cultivo e 10 sem cultivo.

\section{Sistema de irrigação}

O sistema de irrigação foi composto por dois reservatórios d'água com capacidade de $1 \mathrm{~m}^{3}$ cada, acoplados em sistema de vasos comunicantes (Figura 1).

A água era pressurizada por um conjunto eletrobomba com potência de $0,735 \mathrm{~kW}(1 \mathrm{cv})$. O sistema de filtragem foi composto por um filtro de discos com filtragem de 86 micra. Após a filtragem, a água era conduzida até cavaletes, por meio de tubulação em PVC subterrânea. Seqüencialmente, após os cavaletes, existiam duas linhas de distribuição em tubos de polietileno, as quais alimentavam os microtubos conectados aos segmentos dos tubos gotejadores. Para a coleta de dados ou determinação da vazão individual de cada gotejador, criou-se uma rede hidráulica que conduzia a água a apenas um gotejador por vez, por meio de mangueira conectada após o sistema de filtragem, retornando a vazão excedente aos reservatórios.

\section{Determinação da vazão dos emissores}

Para a determinação da vazão individual dos gotejadores, utilizou-se de medidor magnético indutivo, capaz de medir vazões na faixa de 0 a $10 \mathrm{~L} \mathrm{~h}^{-1}$, com precisão de $0,3 \%$. Como cada gotejador era abastecido isoladamente, foi possível determinar a vazão individual de cada emissor, desconectando o microtubo de abastecimento de cada gotejador da rede de PVC e conectando-o ao medidor de vazão.

As datas de início de cada leitura foram: $1^{\circ}-7,1^{\underline{0}}-9,1^{1^{\circ}}-10,1^{\circ}-11$ e $1^{\circ}-12$ do ano de 2001 . Essas leituras foram numeradas de 1 a 5 nas Figuras 2 a 9. Após o período de coleta sequiencial de dados, optou-se por continuar com a estrutura física e aplicação dos tratamentos ativos, o que permitiu efetuar uma leitura 12 meses após a instalação do experimento e que constitui a leitura 6, nas Figuras 2 a 9. 


\section{Parâmetros avaliados}

\section{Coeficiente de variação de vazão (CVQ)}

Realizou-se o cálculo do CVQ para todos os modelos de emissores utilizados no ensaio, em todos os tratamentos [eq.(1)]. Esse coeficiente foi utilizado com o nome de coeficiente de variação de vazão, dado que, como o coeficiente de variação de fabricação (CVF), só poderia ser empregado em amostra de emissores novos.

$$
\mathrm{CVQ}=\mathrm{S} / \mathrm{q}_{\mathrm{m}}
$$

em que,

CVQ - coeficiente de variação de vazão;

$\mathrm{S}$ - desvio-padrão da amostra, e

$\mathrm{q}_{\mathrm{m}}$ - vazão média da amostra, $\mathrm{L} \mathrm{h}^{-1}$.

\section{Vazão relativa $(\mathbf{Q R})$}

Esse índice refere-se às vazões iniciais de cada modelo no instante da realização da primeira leitura. Foi obtido dividindo-se a vazão em qualquer instante pela vazão inicial do emissor [eq.(2)].

$$
\mathrm{QR}=\mathrm{q}_{\mathrm{a}} / \mathrm{q}_{\mathrm{i}}
$$

em que,

QR - vazão relativa;

$\mathrm{q}_{\mathrm{a}}$ - vazão atual, $\mathrm{L} \mathrm{h}^{-1}$, e

$\mathrm{q}_{\mathrm{i}}$ - vazão inicial, $\mathrm{L} \mathrm{h}^{-1}$.

\section{RESULTADOS E DISCUSSÃO}

\section{Emissor modelo A}

Observa-se que o desempenho do emissor A, no que se refere ao coeficiente de variação de vazão (CVQ) inicial, apresentou boa uniformidade geral. Na testemunha $30 \mathrm{~cm}$, ocorreu CVQ inicial superior aos demais. O CVQ inicial de todos os emissores desse modelo, para todos os tratamentos (amostras com 60 indivíduos), foi de 8,6\%. Observa-se que o CVQ geral apresentou pior desempenho no tratamento CFS30, com pico na sexta leitura (Figura 2).

Para todos os tratamentos, observou-se queda de vazão na quinta leitura e no tratamento úmido. Essa redução foi mais acentuada quando da realização da leitura 6, com reduções de 33 e $43 \%$ para as profundidades de instalação de 15 e $30 \mathrm{~cm}$, respectivamente, em relação à QR inicial. Não se observou, até a realização da penúltima leitura, efeito pronunciado dos tratamentos de umidade do solo e profundidade de instalação do gotejador.

A testemunha não apresentou variações significativas ao longo do experimento, evidenciando que as reduções de vazão observadas foram relacionadas à intrusão de raízes no gotejador. 


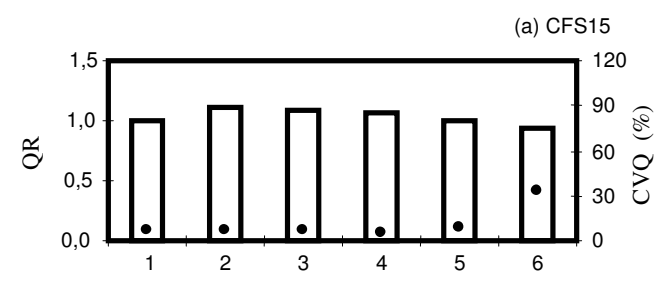

(c) CFU 15

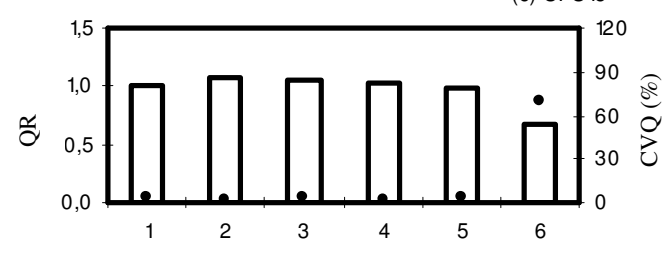

(e) TT15

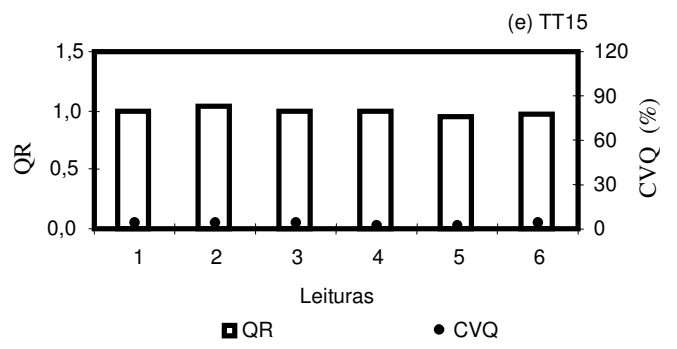

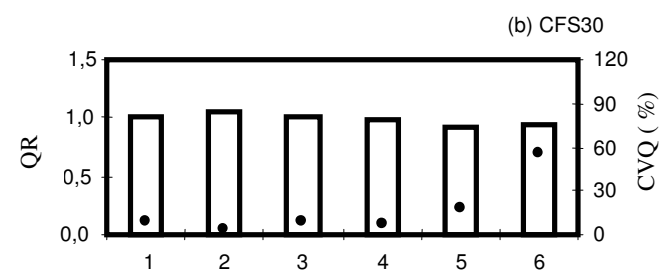

(d) CFU30
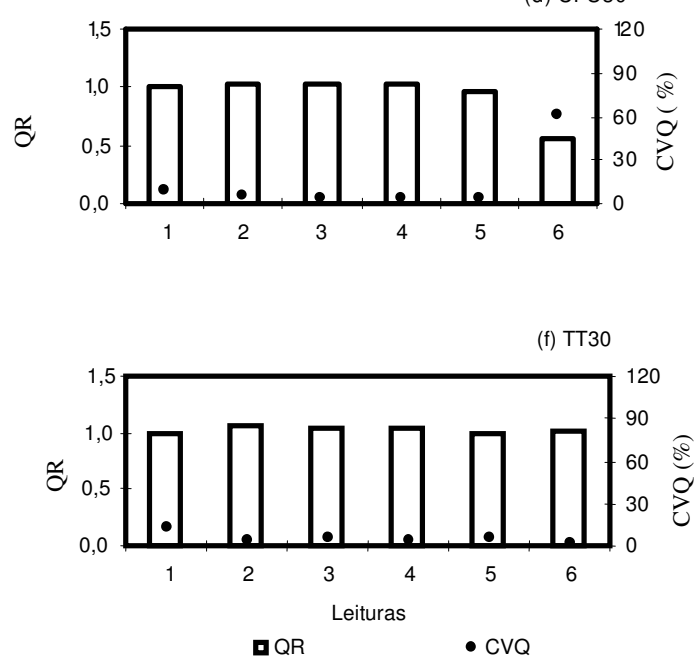

FIGURA 2. Vazão relativa (QR) e coeficiente de variação dos dados de vazão (CVQ) do modelo A, em função dos tratamentos avaliados.

\section{Emissor modelo B}

Esse modelo de emissor apresentou CVQ inicial geral igual a 7,3\% para todos os emissores em todos os tratamentos. Até a quinta leitura, o comportamento do CVQ manteve-se entre 5 e $10 \%$ para todos os tratamentos, sendo exceção apenas as leituras 4 e 5 do tratamento CFU15; tal comportamento deu-se em função de alguns emissores, que apresentaram redução de vazão superior aos demais. Essa uniformidade de aplicação não se manteve após a leitura 5, uma vez que todos os tratamentos de umidade e profundidade de instalação apresentaram elevados valores de CVQ na leitura 6, sendo tal desuniformidade superior no tratamento CFS30. Pode-se inferir, contudo, que o tratamento CFU15 apresentou destaque no que se refere ao efeito dos tratamentos, pois nesse caso ocorreu a maior redução de vazão e o pior desempenho quanto ao parâmetro CVQ (Figura 3).

Diferentemente do modelo anterior, para esse modelo ocorreu maior igualdade de redução de vazão entre os tratamentos seco e úmido, quando se considera a sexta leitura de vazão. No entanto, no tratamento úmido, a redução de vazão foi evidenciada já por ocasião da leitura 5 . O elevado valor do CVQ observado na profundidade de $15 \mathrm{~cm}$ do tratamento-testemunha indica que, nesse modelo, o efeito solo possa ter sido mais pronunciado. 


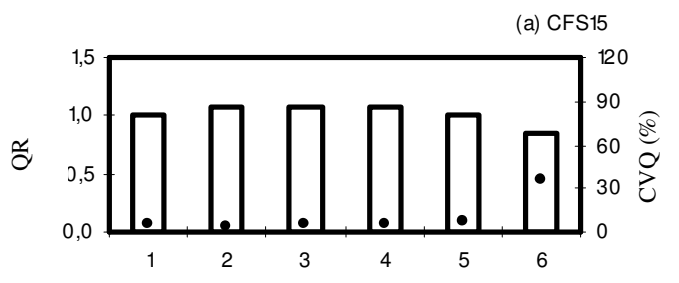

(c) CFU15

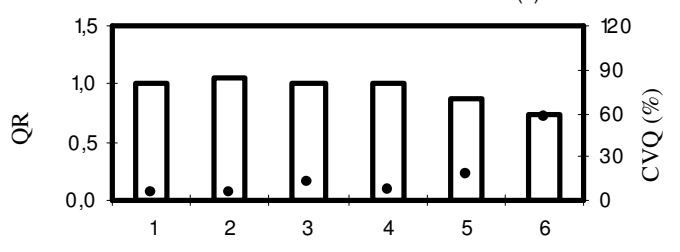

(e) TT15

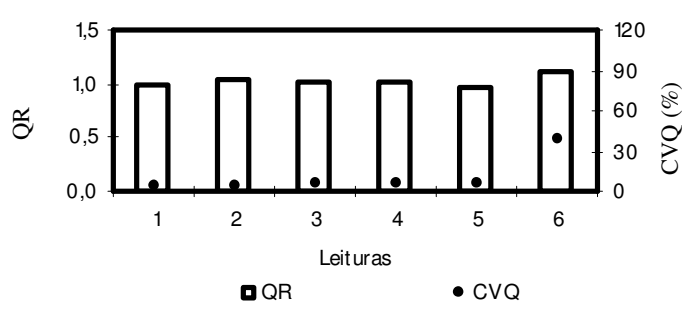

(b) CFS30

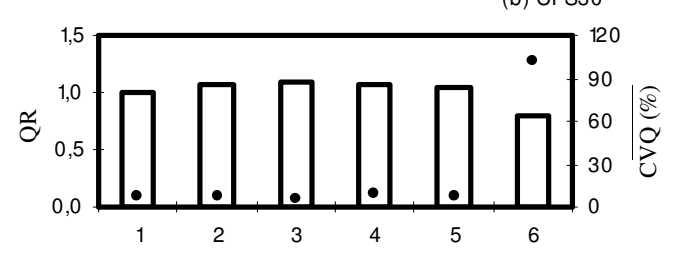

(d) CFU30

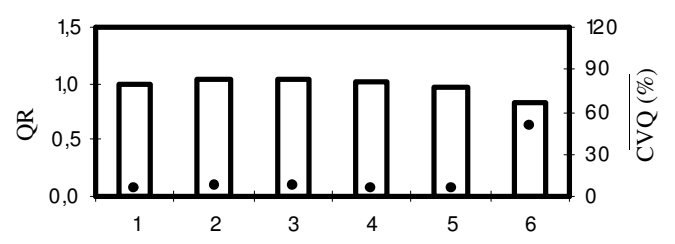

(f) TT30

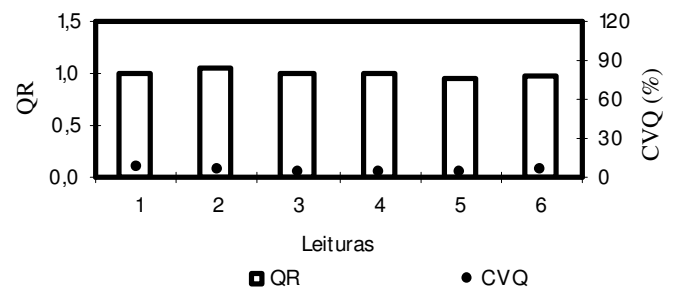

FIGURA 3. Vazão relativa (QR) e coeficiente de variação dos dados de vazão (CVQ) do modelo B, em função dos tratamentos avaliados.

\section{Emissor modelo $\mathbf{C}$}

O valor do CVQ inicial geral para esse modelo de emissor foi de 8,4\%. Os valores de CVQ inicial nos tratamentos e nas testemunhas apresentaram valores médios entre 10 e 13\%; no tratamento seco, a desuniformidade foi mais acentuada, com variação de 13 a $16 \%$ para os valores iniciais de vazão. Não ocorreram picos nos valores do CVQ, demonstrando estabilidade de vazão. Observam-se maiores valores de CVQ para o tratamento café seco $30 \mathrm{~cm}$; porém o valor do CVQ para a primeira leitura já se apresentava elevado (Figura 4).

O modelo mostrou leve tendência de redução de vazão entre as leituras 1 e 5 . No entanto, para a leitura 6, o mesmo apresentou os maiores níveis de redução de vazão entre todos os modelos avaliados, com valores de QR variando de 0,31 a 0,67. De modo contrário ao observado no modelo A, os maiores níveis de redução de vazão ocorreram no tratamento seco.

O tratamento-testemunha apresentou reduzida variação de vazão, bem como valores baixos de CVQ para todo o período do experimento. 

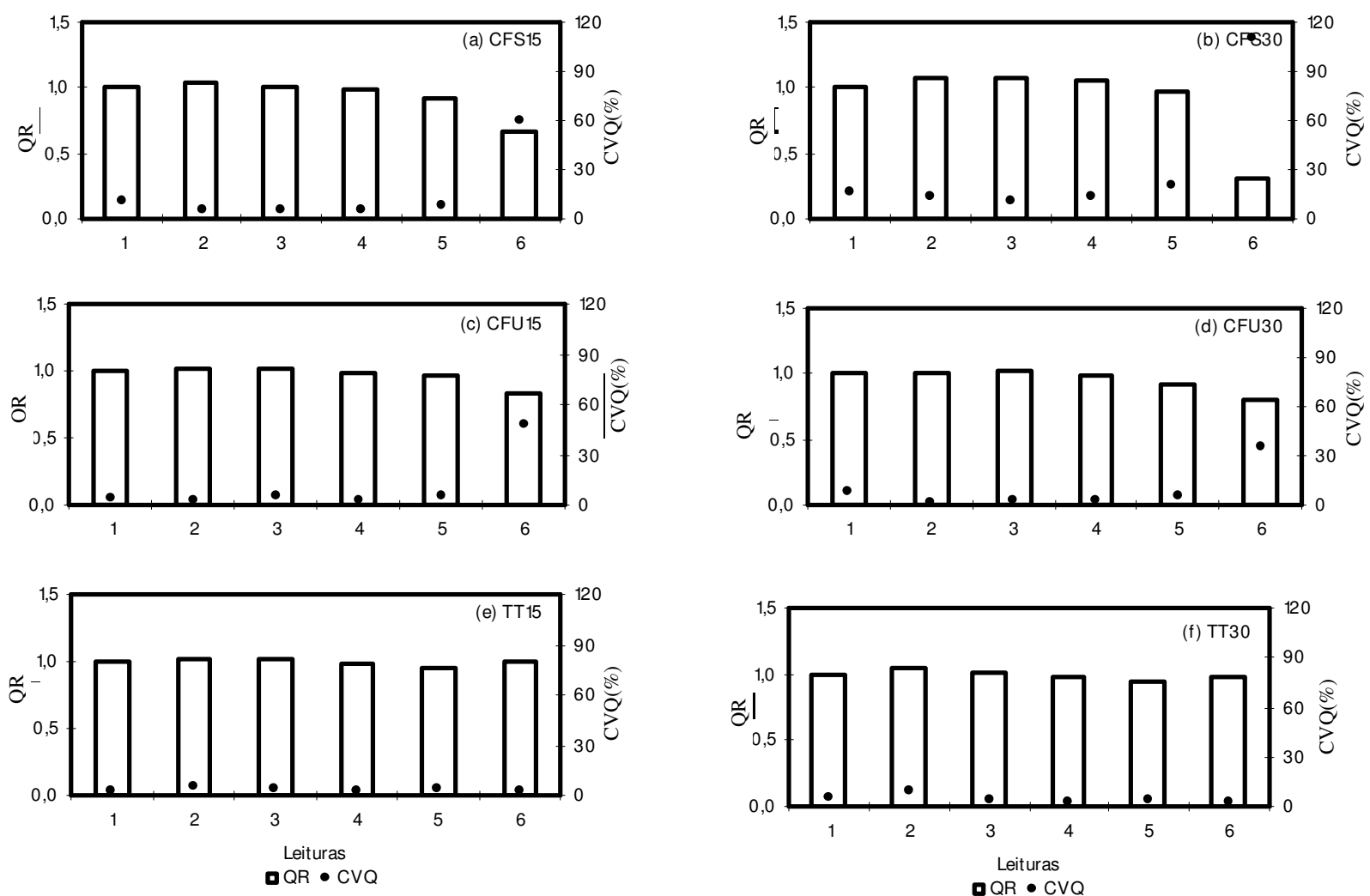

FIGURA 4. Vazão relativa (QR) e coeficiente de variação dos dados de vazão (CVQ) do modelo C, em função dos tratamentos avaliados.

\section{Emissor modelo D}

Os valores de CVQ inicial geral e inicial dos tratamentos e testemunhas apresentaram-se uniformes. O valor do CVQ inicial geral foi de 6,2\% e, de maneira geral, o CVQ dos tratamentos apresentaram-se próximos desse valor, demonstrando variabilidade de vazão reduzida. Observam-se picos no CVQ no tratamento CFU30. Isso se deveu à redução total de vazão de apenas um emissor (repetição 5), o qual inicialmente apresentava vazão normal e posteriormente sofreu redução de vazão, chegando à obstrução total. $O$ coeficiente de variação apresenta elevada sensibilidade a valores altamente discrepantes, no caso a vazão nula, o que reflete no grande aumento do CVQ apresentado. No caso da média, a mesma apresenta menor sensibilidade a valores discrepantes, como mostra sua menor variação em função do mesmo dado (Figura 5).

Com exceção do tratamento CFU30, os valores de QR apresentaram pequena variação até a quinta leitura de vazão. Tais reduções se mostraram significativas na sexta leitura, e os tratamentos CFU15 e CFU30 se destacaram em relação aos tratamentos CFS15 e CFS30. Nos primeiros, a redução de vazão foi de 49 e 59\%, respectivamente, enquanto para o segundo grupo essa redução foi de 9 e $28 \%$, respectivamente.

Os tratamentos-testemunha apresentaram baixos valores de CVQ e pequena variação de vazão relativa $(\mathrm{QR})$ durante todo o período do experimento. 

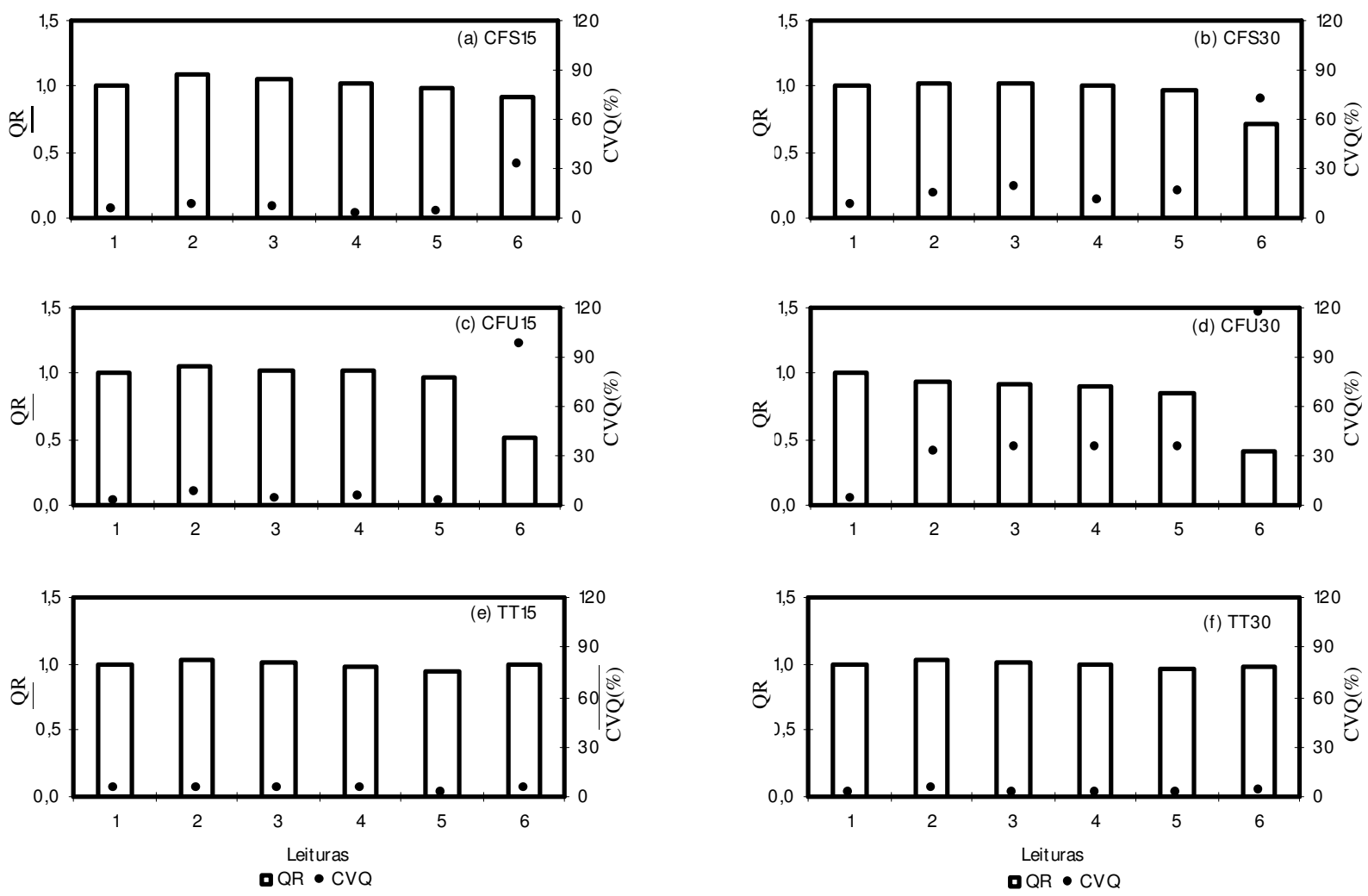

FIGURA 5. Vazão relativa (QR) e coeficiente de variação dos dados de vazão (CVQ) do modelo D, em função dos tratamentos avaliados.

\section{Emissor modelo E}

O desempenho desse modelo de emissor, quanto ao parâmetro CVQ inicial, apresentou desuniformidade entre tratamentos, sendo o CVQ inicial geral de 14,8\%. Observa-se, para todos os tratamentos, tendência inicial de aumento de vazão e posteriormente de redução de vazão, pouco evidente nas testemunhas. Para todos os tratamentos, com exceção do CFU15, os valores de CVQ se mantiveram sempre abaixo de $10 \%$ até a leitura 5. Na última leitura, todos os tratamentos, com exceção do TT30, revelaram significativa desuniformidade das vazões medidas, com valores de CVQ variando de 32\%, no tratamento TT15, a 119\% no tratamento CFU30 (Figura 6).

Os valores de CVQ para os tratamentos-testemunha se mantiveram entre 5 e $10 \%$ durante todo o período do experimento, com exceção da última leitura do tratamento TT15, o qual apresentou valor de CVQ de 32\%. Tais resultados, aliados à pequena variação de vazão nesses tratamentos, evidenciam que as reduções de vazão observadas nos demais tratamentos estão relacionadas ao processo de intrusão de raízes no emissor.

Os valores de QR na última leitura, para os vasos com cultivo, foram os mais baixos entre todos os modelos avaliados, mostrando elevada suscetibilidade ao processo de intrusão radicular. $\mathrm{O}$ tratamento úmido resultou nos maiores níveis de redução, para as duas profundidades de instalação avaliadas, com valores de QR de 0,22 e 0,30 no CFU15 e CFU30, respectivamente. 

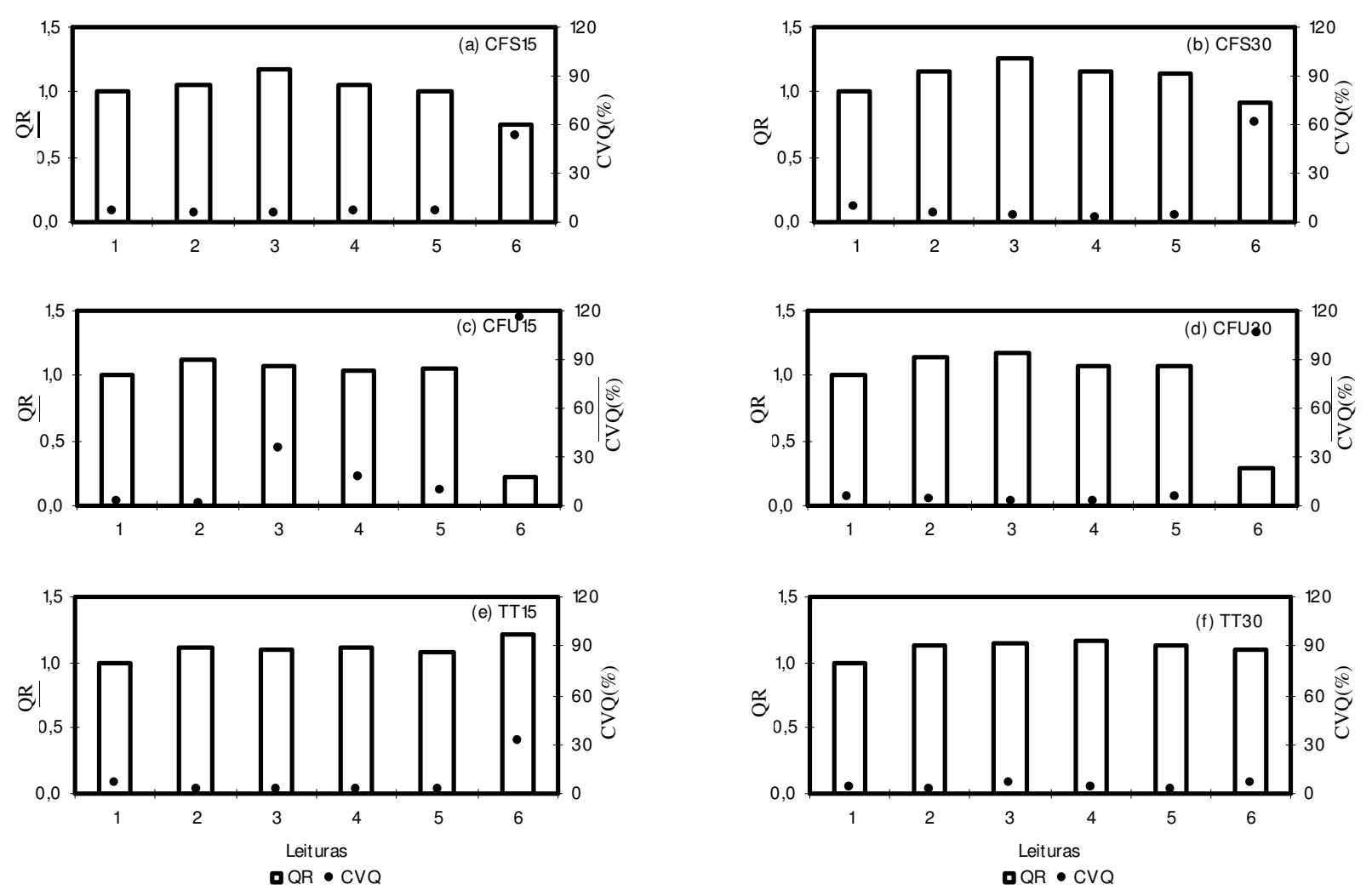

FIGURA 6. Vazão relativa, QR, e coeficiente de variação dos dados de vazão, CVQ, do modelo E, em função dos tratamentos avaliados

\section{Emissor modelo F}

Até a quinta leitura, esse modelo apresentou CVQ inicial geral para os tratamentos e para as testemunhas próximo de 8,8\%. Em todos os tratamentos, houve leve tendência de redução de vazão. Não se observou nenhum emissor com redução total de vazão. Observou-se também que a vazão real desse emissor esteve próxima da vazão nominal fornecida pelo fabricante. Não se observaram vazões extremas, bem como valores elevados do CVQ. Os tratamentos não apresentaram evidência até a última determinação de vazão (Figura 7).

Considerando a última leitura, esse modelo apresentou, juntamente com o modelo B, os menores níveis de redução de vazão. Os valores mínimos de QR foram observados nos tratamentos CFS30 e CFU30, sendo tais valores de 0,57 e 0,74 , respectivamente. 

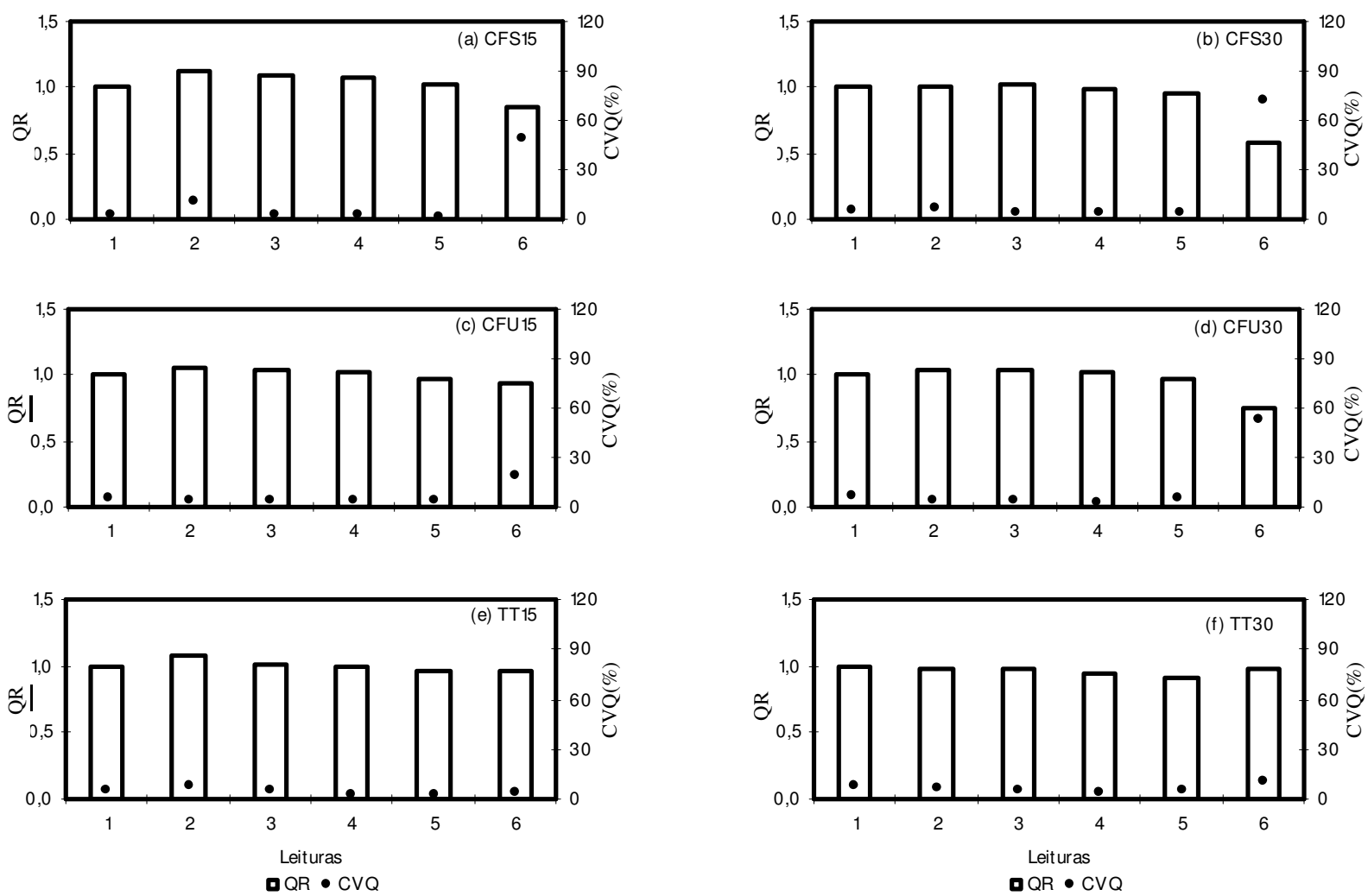

FIGURA 7. Vazão relativa, QR, e coeficiente de variação dos dados de vazão, CVQ, do modelo F, em função dos tratamentos avaliados.

\section{Emissor modelo G}

O CVQ inicial geral para esse modelo de emissor foi de 11,2\%. Já o CVQ inicial dos tratamentos apresentou valores próximos do CVQ inicial geral. Houve tendência geral de redução de vazão para todos os tratamentos e testemunhas, apresentando valor mínimo em CFU30. Foram observados valores extremos do parâmetro CVQ para o tratamento úmido, nas duas profundidades avaliadas. Na última leitura de vazão, esse modelo apresentou, no tratamento CFU30, o maior nível de desuniformidade entre todos os gotejadores avaliados, com um CVQ de 200\% (Figura 8).

Os valores de CVQ e QR apresentados pelo tratamento-testemunha, para as duas profundidades de instalação avaliadas, demonstram que a redução de vazão apresentada pelo modelo está relacionada ao processo de intrusão de raízes.

Até a leitura 5, que corresponde a um período de 120 dias, os diversos modelos de gotejadores avaliados não apresentaram níveis de variação de vazão significativos, em função dos diferentes níveis de umidade do solo e profundidade de instalação dos mesmos. Considerando a leitura 6, realizada 180 dias após a leitura 5, o efeito dos tratamentos sobre os gotejadores mostrou-se evidente, revelando diferenças de comportamento entre os modelos. 

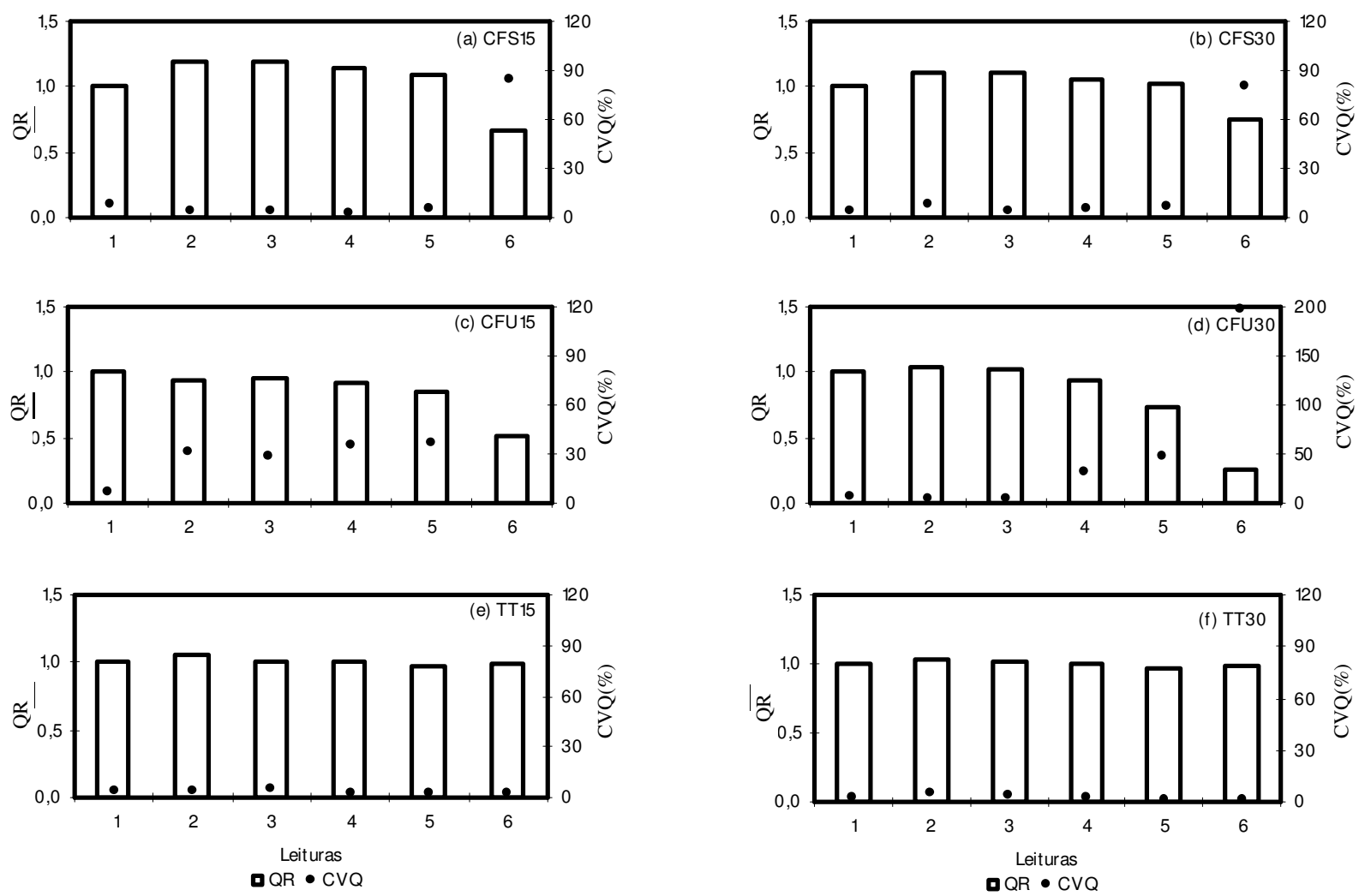

FIGURA 8. Vazão relativa, QR, e coeficiente de variação dos dados de vazão, CVQ, do modelo G, em função dos tratamentos avaliados

Assim, calculando-se a média dos valores de QR, na leitura 6, dos tratamentos úmido e seco, e nas duas profundidades estudadas, podem-se agrupar esses modelos, em termos de suscetibilidade à intrusão de raízes, em três grupos: no primeiro, formado por gotejadores que apresentaram os menores níveis de redução de vazão, enquadram-se os modelos A, B e F; no segundo grupo, de comportamento intermediário, se enquadram os modelos $\mathrm{C}$ e $\mathrm{D}$, e no terceiro, formado pelos modelos que apresentaram os maiores níveis de redução de vazão, enquadram-se os modelos E e G. Na definição desse agrupamento, considerou-se o valor médio de QR da leitura 6, apenas dos tratamentos úmido e seco. Dessa forma, os valores médios de QR variaram de 0,77 a 0,80 para o primeiro grupo, de 0,63 a 0,65 para o segundo grupo e um valor de 0,55 para os dois gotejadores do terceiro grupo. Na Figura 9, a vazão média de cada leitura, calculada como explicitada acima, é comparada à vazão nominal do respectivo gotejador (Tabela 1) e permite visualizar o grau de suscetibilidade dos diferentes modelos.

De modo geral, o tratamento úmido resultou em maiores níveis de redução de vazão, tendo sido esse comportamento bem definido para os modelos A, D, F e G. Somente nos modelos C e F, o tratamento seco resultou em maiores níveis de redução de vazão. Esses resultados contrariam o proposto por MEAD (2002), para o qual o sistema radicular não invadiria emissores em solos saturados ou próximos à saturação, onde não haja uma depleção elevada de água no solo.

O efeito da profundidade de instalação do gotejador não foi tão intenso quanto ao ocorrido para os tratamentos de umidade do solo. Embora com menor magnitude, a profundidade de instalação de $30 \mathrm{~cm}$ resultou em maiores níveis de redução de vazão que a profundidade de $15 \mathrm{~cm}$. Esse fato pode ser observado no tratamento úmido dos modelos A (Figuras 2c e 2d ), D (Figuras 5c e 5d ) e G (Figura $8 \mathrm{c}$ e $8 \mathrm{~d}$ ). Mesmo nos casos em que o tratamento seco foi o que resultou em menores valores de $\mathrm{QR}$, a profundidade de $30 \mathrm{~cm}$ foi a que apresentou os maiores níveis de redução de vazão, sendo esse o caso dos gotejadores C (Figuras 4a e 4b ) e F (Figuras 7a e 7b). 

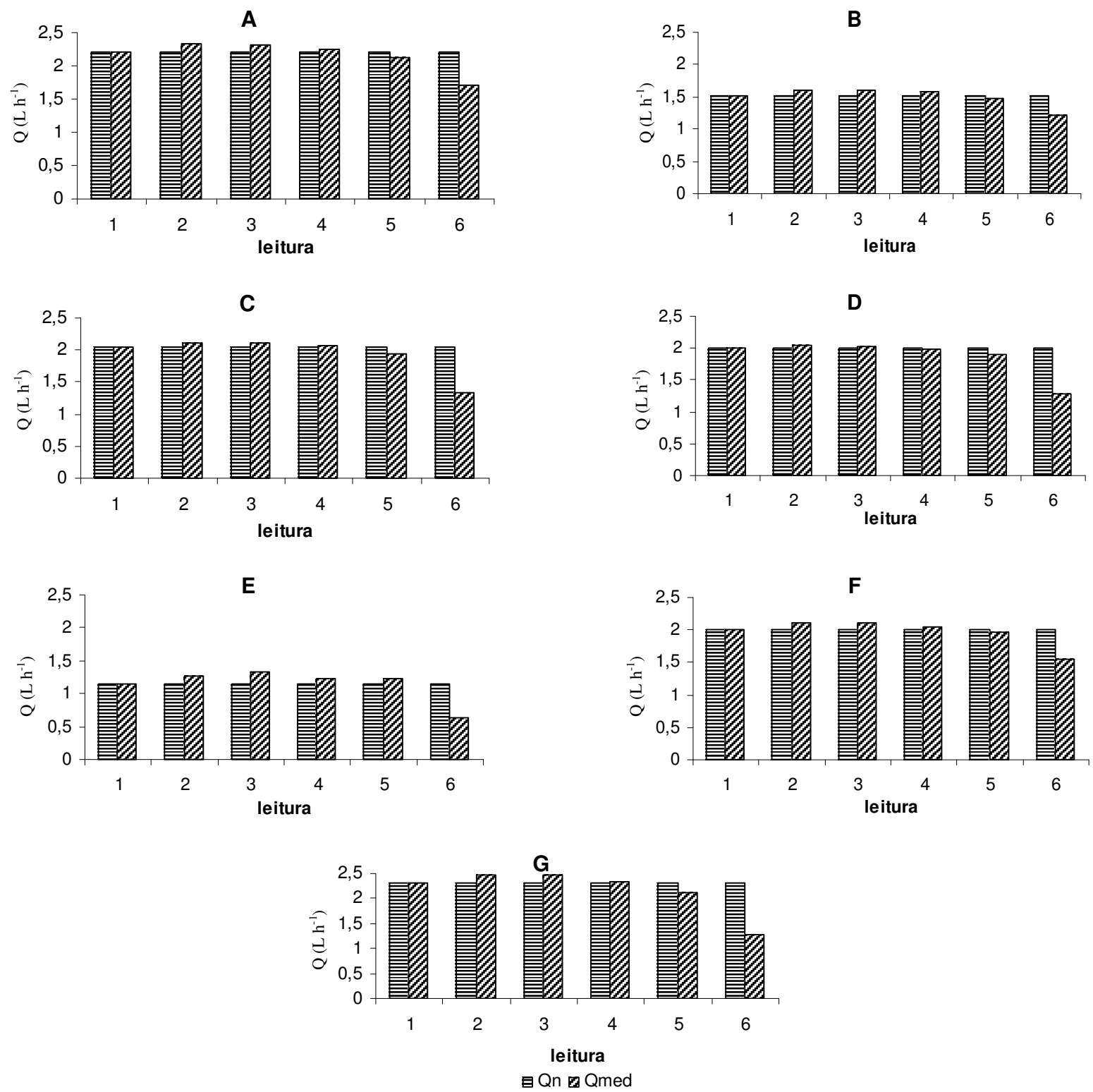

FIGURA 9. Comportamento da vazão média (Qmed) em cada leitura, em relação à vazão nominal (Qn) dos modelos de gotejador avaliados.

Em trabalho similar, conduzido com a cultura da cana-de-açúcar e com gotejadores idênticos aos aqui utilizados, RESENDE (2003) observou comportamento idêntico quanto ao desempenho dos modelos, em termos do agrupamento aqui apresentado. Da mesma forma, o mesmo autor evidenciou maior ocorrência de redução de vazão em gotejadores funcionando em regime de umidade do solo mais elevado e maior profundidade de instalação dos gotejadores.

\section{CONCLUSÕES}

A hipótese de que o sistema radicular sob estresse hídrico seria mais agressivo ao gotejamento enterrado não se confirmou de maneira conclusiva. $\mathrm{O}$ sistema radicular das plantas bem irrigadas apresentou um notável vigor que poderá ser também bastante agressivo aos emissores.

Variações de vazão nos gotejadores enterrados, devido às raízes, foram mais freqüentes na profundidade de $30 \mathrm{~cm}$. 
Diferentes modelos de gotejadores apresentaram diferentes graus de sensibilidade às variações de vazão no gotejamento subsuperficial.

Quanto ao aspecto construtivo (barreiras físicas), nenhum dos emissores ensaiados demonstrou possuir mecanismos que impeçam efetivamente a penetração das raízes em seu interior, mesmo aqueles que usualmente são recomendados para uso no gotejamento subsuperficial.

\section{REFERENCIAS}

AYARS, J.E.; PHENE, C.J.; HUTMACHER, R.B.; DAVIS, K.R.; SCHONEMAN, R.A.; VAIL, S.S.; MEAD, R.M. Subsurface drip irrigation in row crops: a review of 15 years of research at the Water Management Research Laboratory. Agricultural Water Management, Amsterdam, v.42, n.1, p.1-27, 1999.

GHAEMI, A.; CHIENG, S. Emitter clogging and hydraulics in micro-irrigation lines. In: ASAE ANNUAL INTERNATIONAL MEETING, 1999, Toronto. St Joseph: ASAE, 1999 (Paper 992211).

GILBERT, R.G.; FORD, H.W. Operational principles/emitter clogging. In: NAKAYAMA, F.S.; BULKS, D.A. Trickle irrigation for crop production. Amsterdam: Elsevier, 1986. p.142-63.

MEAD, R. Root intrusion prevention. Disponível em: <www.microirrigationforum.com/new/archives/rootpre.html>. Acesso em: 10 jan. 2002. RESENDE, R.S. Intrusão radicular e efeito de vácuo em gotejamento enterrado na irrigação de canade-açúcar. 2003. 124 f. Tese (Doutorado em Irrigação e Drenagem) - Escola Superior de Agricultura "Luiz de Queiroz", Universidade de São Paulo, Piracicaba, 2003.

RUSKIN, R.; FERGUSON, K.R. Protection of subsurface drip irrigation systems from root intrusion. Disponível em: http://www.geoflow.com/root\%20tfn/IA\%20paper\%20TFN\%20applications\%20final.html. Acesso em: 21 maio 2000.

SOLOMON, K.H. Global uniformity of trickle irrigation system. Transaction of the ASAE, St. Joseph, v.28, n.4, p.1151-8, 1985.

SUAREZ-REY, E.; CHOI, C.Y.; WALLER, P.M. Feasibility of subsurface drip irrigation on turf in Arizona. In: ASAE ANNUAL INTERNATIONAL MEETING, 1999, Toronto. St. Joseph: ASAE, 1999. (Paper 992251)

ZOLDOSKE, D.; STRIEGLER, R.K.; BERG, G.T.; JORGENSON, G.; LAKE, C.B.; GRAVES, S.G.; BURNETT, D.M. Evaluation of trellis system and subsurface drip irrigation for wine grape production: a progress report. 1998: Center for Irrigation Technology. Disponível em: <www.cati.csufreno.edu/cit>. Acesso em: 10 jan. 2002. 